\title{
Publisher Correction: Catalyst control over sixfold stereogenicity
}

Xingxing Wu, Reto M. Witzig (D), Rodolphe Beaud, Christian Fischer (D), Daniel Häussinger (1) and Christof Sparr (D)

Correction to: Nature Catalysis https://doi.org/10.1038/s41929-021-00615-Z, published online 27 May 2021.

In the Supplementary Information file originally published with this Article, pages 1-132 were missing. This error has now been corrected.

Published online: 3 June 2021

https://doi.org/10.1038/s41929-021-00645-7

(c) The Author(s), under exclusive licence to Springer Nature Limited 2021 